\title{
Surface Modification of YW2 Cemented Carbide Cutting Tool by High Current Pulsed Electron Beam
}

\author{
Changsheng $\mathrm{LOU}^{1}{ }^{*}$, Yao ZHANG ${ }^{2}$, Xiao LYU ${ }^{1}$, Jinglong GAO ${ }^{1}$, Qiang WANG ${ }^{2}$ \\ ${ }^{1}$ School of Materials Science and Engineering, Shenyang Ligong University, Shenyang 110159, \\ People's Republic of China \\ ${ }^{2}$ Key Laboratory of Electromagnetic Processing of Materials (Ministry of Education), Northeastern University, \\ Shenyang 110819, People's Republic of China
}

crossref http://dx.doi.org/10.5755/j01.mm.21.2.6748

Received 21 March 2014; accepted 08 November 2014

\begin{abstract}
Surface modification of YW2 cemented carbide cutting tool was carried out through high current pulsed electron beam (HCPEB) with different pulsed times, and the microstructure, mechanical properties and cutting performance is also investigated in this work. The evolution of phase composition and morphology of tool was tested by means of XRD and SEM, and the microhardness was measured. The results showed that the content of metastable phase $\mathrm{Co}_{3} \mathrm{~W}_{3} \mathrm{C}$ is increased in tool surface after beam irradiation. The metastable phase and residual compressive stress induced by HCPEB treatment modified the microhardness of YW2 turning insert dramatically. The cutting performance of YW2 turning insert with 40 times irradiation was examined and compared with original one by machining Ti-6Al-4V alloy bar. It is found that the irradiated YW2 tool increased cutting speed than that of un-irradiated one along with serious wear. Keywords: surface modification, YW2 cemented carbide tool, mechanical property, cutting performance.
\end{abstract}

\section{INTRODUCTION}

Titanium alloys are the most attractive metallic materials for aircraft, medicine and engineering industries, due to their high tensile strength and toughness, as well as extraordinary corrosion resistance $[1,2]$. But titanium alloys has some problems in manufacturing as their poor machinability, which attributes to the low thermal conductivity and high chemical activity as cutting tools [3-5]. The cutting technology of titanium alloy is interesting for technicians who engage in machine manufacture and pay much attention on enhancing the strength, thermal conductivity and tribological property of titanium alloy as cutting tools in recent years [6]. Cemented carbide inserts become the popular solution at present. Furthermore, addition of a small quantity of Ta and Ti elements may improve the hardness and the wear resistance of inserts as the same time guarantees the basic toughness [7].

High current pulsed electron beam technique (HCPEB), as a novel and valid method used for material surface modification, provide elevated surface properties for irradiated materials [8-11]. The electron beam generates intense and super fast melting, evaporation, solidification, and even ablation on the surface of target materials together with the formation of thermal stress and shock waves. The energy intensity of pulse electron beam applied to materials is normally up to $\left(10^{8}-10^{9}\right) \mathrm{W} / \mathrm{cm}^{2}$. Comparing to the other conventional surface treatment techniques, HCPEB technique can improve the mechanical properties of irradiated metallic materials faster and more efficiently. The effects of HCPEB on materials have been investigated by many researchers $[12,13]$. For example,

\footnotetext{
*Corresponding author. Tel.: +86-24-24680681; fax: +86-24-24680809.
} E-mail address: chsh_lou@163.com (C. Lou) the surface roughness of pure $\mathrm{Ti}$ was modified and the nanohardness in the surface modified layer was improved. The modifications can be attributed to the dislocations and fine grains in the modified layer induced by HCPEB [12]. The HCPEB irradiation led to the increasing of WC $6 \%$ Co cemented carbide microhardness, and the samples showed significant improvements in wear resistance [14]. The good wear resistance and high microhardness are necessary for cutting tools. Recently, surface strengthening of hard alloys by HCPEB is of great interest in industry $[15,16]$.

The aim of this work is to enhance the cutting performance of YW2 turning insert modified by HCPEB irradiation, and study the evolution of microstructure and mechanical properties of YW2 cemented carbide inserts modified by HCPEB irradiation, finally to find out the correlation of treatment parameters and machining property of YW2 cutting tool.

\section{EXPERIMENTAL DETAILS}

The samples used in the experiments were 31303C type YW2 cemented carbide turning inserts, which were fabricated by Zhuzhou Cemented Carbide Cutting Tools Co. Ltd. (China). The chemical composition of YW2 alloy is listed in Table 1. Prior to HCPEB treatment, the inserts were washed by acetone and absolute ethyl alcohol. Then the inserts were irradiated through "SOLO" type HCPEB system (Institute of High Current Electronics SB RAS, Tomsk, Russia), with the following working parameters: accelerating voltage, $13 \mathrm{kV}$; energy density, up to $3 \mathrm{~J} / \mathrm{cm}^{2}$; pulse duration, $\sim 5 \mu \mathrm{s}$; pulse frequency, $1 \mathrm{~Hz}$; number of pulses, 20, 30 and 40 times, respectively.

The morphology of inserts was observed using scanning electron microscope (SEM, Hitachi S3400N). The phase composition was analyzed by X-ray diffractometer (XRD, 


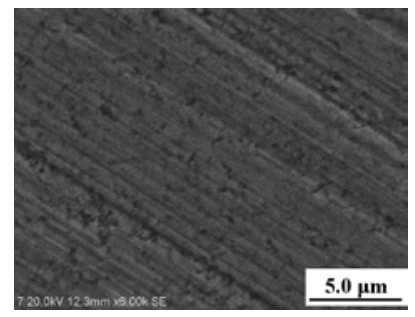

a

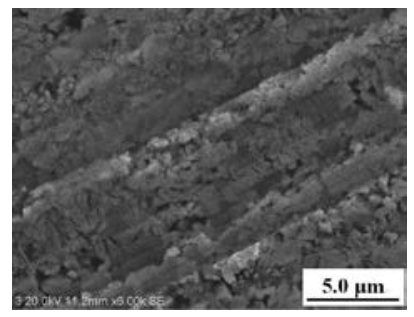

b

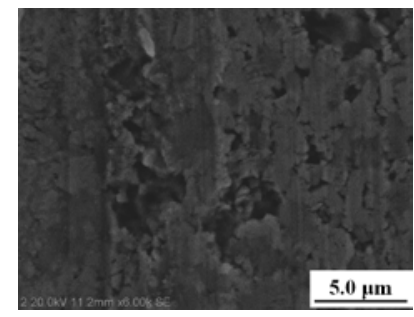

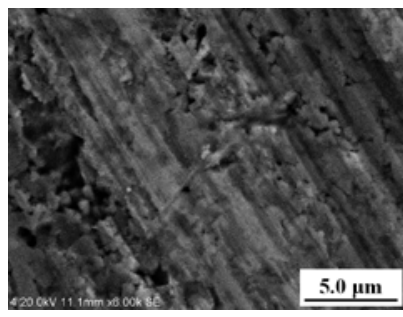

d

Fig. 1. Top morphologies of YW2 cemented carbide inserts without and with beam irradiation: a - 0, b - 20, c - 30 and d - 40 times

Rigaku Ultima IV). Microhardness was tested by FM-300 tester with a Vickers indenter under the load of 50 gf and the time of $5 \mathrm{~s}$. Roughness of inserts was examined using TR100 tester. Ti-6Al-4V orthogonal turning tests were carried out with the following parameters: feed (fa), $0.2 \mathrm{~mm}$; depth (ap), $0.3 \mathrm{~mm}$.

Table 1. Chemical composition of YW2 alloy, wt. \%

\begin{tabular}{|c|c|c|c|}
\hline WC & Co & TiC & TaC \\
\hline 82 & 8 & 6 & 4 \\
\hline
\end{tabular}

\section{RESULTS AND DISCUSSION}

\subsection{Morphology and roughness}

The morphology of the inserts with and without beam irradiation is shown in Fig. 1. There are obvious grinding cracks on original sample (Fig. 1, a), while the melting craters with different sizes occur on the irradiated samples (Fig. 1, b, c and d). The crater is a typical feature of HCPEB treated metal surfaces [12-13]. With increasing the numbers of pulses, the grinding cracks became blurred due to the occurrence of more and more melting craters. This phenomenon is attributed to the melting ablation of inserts' surface. The pulsed beam generates intense and super fast melting on the surface of YW2 alloys, so the surface of inserts undergoes repeated rapid melting and subsequent solidification during multiple HCPEB treatments. Uglov et al. [17] calculated the temperature profile of WC-15 TiC6 Co hard alloy irradiated by pulsed intense pulsed electron beam with energy density up to $80 \mathrm{~J} / \mathrm{cm}^{2}$. The results of temperatures filed simulation showed that the absorbed electron beam heats pre-surface layer over melting temperature of the alloy components. In this work, the absorbed energy was about $3 \mathrm{~J} / \mathrm{cm}^{2}$ as calculated, and the maximum temperature was $1800 \mathrm{~K}$ approximately. The melting points of different phases in experimental alloy are: WC, $3134 \mathrm{~K}$; TiC, $3433 \mathrm{~K}$; TaC, $4153 \mathrm{~K}$; Co, $1768 \mathrm{~K}$, respectively. The irradiated surface consists of region with contact melting of carbide particles, region of the melt Co phase. The crystal structure of WC is simple hexagonal and distributed in the Co matrix [18]. Due to the low melting point Co, coupled with the existence of the marginal effect, so that the craters distributed in the edge of WC grains mainly.

The roughness of inserts after HCPEB treatment is shown in Fig. 2. The maximum value is $0.39 \mu \mathrm{m}$ in the sample inflicted 30 times irradiation and the minimum one is only $0.14 \mu \mathrm{m}$ after 40 times which is approximately equal to the original state $(0.16 \mu \mathrm{m})$. The reason for the increase of surface roughness with irradiation by 30 pulses is that bigger craters are present on the surface of inserts.

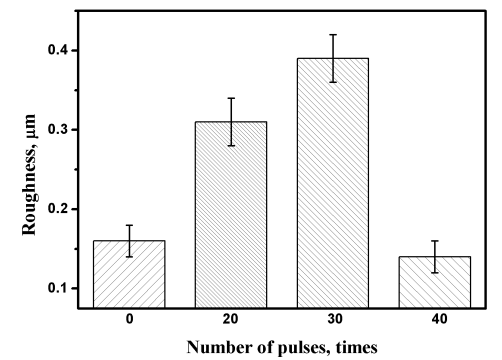

Fig. 2. Roughness of YW2 inserts irradiated at different number of pulses

The inserts irradiated by 30 pulses show a different surface morphology than the others. The flow ability of melted metal during melting induced by HCPEB makes the craters decrease with increase the number of pulses. So the roughness is decreased after 40 pulses. The change of roughness will enhance during melting, evaporation and solidification process with the increase of pulse times by HCPEB. The factors of roughness changed during high current pulsed electron beam treatment were investigated in reference [11].

\subsection{Phase composition}

XRD patterns of YW2 inserts irradiated at different number of pulses are shown in Fig. 3.

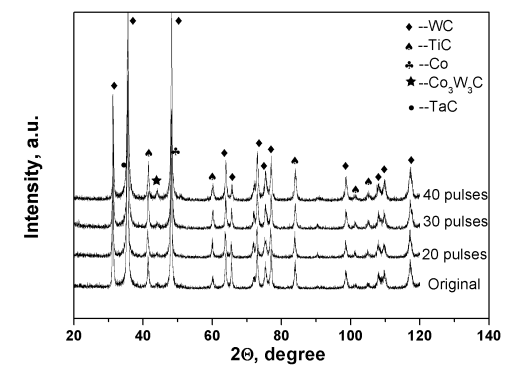

Fig. 3. XRD patterns of the YW2 inserts irradiated at different number of pulses

Besides the strong peaks of $\mathrm{WC}$, Co and TiC, there are weak peaks of $\mathrm{Co}_{3} \mathrm{~W}_{3} \mathrm{C}$ on original insert. After the HCPEB treatments, the $\mathrm{Co}_{3} \mathrm{~W}_{3} \mathrm{C}$ peak became higher than the original one, which indicates more $\mathrm{Co}_{3} \mathrm{~W}_{3} \mathrm{C}$ phases are produced during irradiation. These metastable phases have also been report in other references $[19,20]$. The binding phase of Co will melt during the irradiation by HCPEB and the edge of WC will also melt because of marginal effect. Under the circumstance, the melt Co and WC phase will 
mix together and $\mathrm{Co}_{3} \mathrm{~W}_{3} \mathrm{C}$ new phase will be generated during the rapid cooling processes. With the increase of number of pulses, the amount of intermetallic phase increased.

Meanwhile, the peaks of WC have a little shift to high angle, which implies there being higher residual compressive stress. In addition, the full width at half maximum (FWHM) of main WC phase's peaks in irradiated samples is equal to the original one. X-ray line profile analysis (XLPA) is a powerful method for charactering microstructure of crystalline materials, such as dislocation, size of grain, internal stresses etc. It is reported in [21] that the shift of diffraction peaks is mainly resulted from internal stresses, chemical gradients or planar faults, especially stacking faults and twinning; the broadening of diffraction peaks can be caused by finer grains, microstress and chemical heterogeneities. For the obtained data of original and irradiated specimens in our work, the results of X-ray line profile analysis showed that the average crystallite sizes is not changed and the state of density of dislocation is not changed too, as the values of FWHM are equal. In this case, the shift of diffraction peaks is mainly attributed to the increased residual stress in the insert's surface layer.

\subsection{Microhardness}

The microhardness was measured on the surface and the values are shown in Fig. 4. It's worth noticing that there exhibit significantly hardening effect on the surface of irradiated samples.

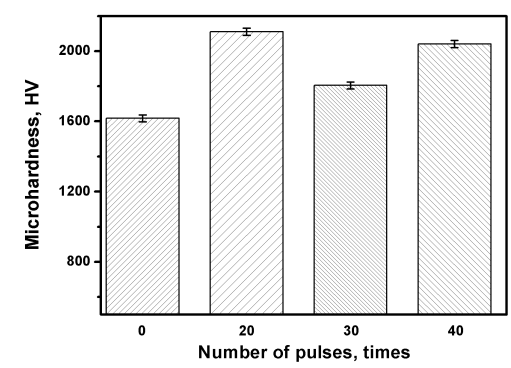

Fig. 4. Microhardness of YW2 inserts irradiated at different number of pulses

It is reported that the hardening effect of alloys induced by HCPEB is attributed to grain refinement, generation of metastable phase, strain hardening etc. As mentioned above, the nearly identical FWHM in all samples' pattern demonstrate the grain size in irradiated inserts is equal to that in un-irradiated ones. As intermetallic compound $\mathrm{Co}_{3} \mathrm{~W}_{3} \mathrm{C}$ is responsible for the higher hardness recorded in this study due to its higher hardness [22].

At the same time, the residual compressive stress induced by HCPEB also increased the hardness. However, the dislocation density has no obvious change after multiple irradiation treatment (as shown in Fig. 3). The deformation hardening may be attributed to the dislocation-free plastic deformation under the rapid and giant shock stress on the irradiated samples. The deformation mechanism $[23,24]$ may interpret the dislocation-free in the irradiation process. The instantaneous heating and followed cooling generates a very huge temperature gradient on the surface, that induced a superspeed plastic deformation. During the reduplicative process, the dislocation movement cannot carry out, and the plastic deformation may rely on the whole atoms movement in the packed plane of WC grains.

\subsection{Machining performance}

The YW2 insert irradiated at 40 pulses was used to execute the machining test, the results were compared to that of the original ones. The results showed that the cutting speed of original YW2 insert was $77 \mathrm{~m} / \mathrm{min}$, and the insert irradiated at 40 times was $88 \mathrm{~m} / \mathrm{min}$.

The index for estimating the wear out of inserts is the average width (VB) of major flank of cutting tools. It is found that the VB with 40 times irradiation is $0.14 \mathrm{~mm}$, which is lower than the original one $(0.15 \mathrm{~mm})$ after about $180 \mathrm{~m}$ cutting length. While the cutting length increased to about $\sim 360 \mathrm{~m}$, the VB value of irradiated insert changes to about $0.5 \mathrm{~mm}$ sharply. The observation of wear morphology indicated the tipping occurred in the nose. The tipping resulted from the brittle phase rupture. The metastable phases are with lower toughness and are fragile; it is possible to suppress lowering of toughness of alloy as extensively as possible by causing minute separation, and then cause harmful effect on the wear performance of tool during the cutting processing.

\section{CONCLUSIONS}

The evolution of top morphology, roughness, microhardness and phase composition of YW2 inserts induced by HCPEB treatment were investigated in this research. And the cutting performance of irradiated inserts was compared to the original ones. The results showed that the beam irradiation caused the rapid remelting of surface, and changed the roughness of samples. More $\mathrm{Co}_{3} \mathrm{~W}_{3} \mathrm{C}$ phases are produced during irradiation, which is responsible for the hardening effect by HCPEB treatment. The other factor impact on the increasing of microhardness is straindeformation induced by giant shock wave during the process. The YW2 insert irradiated with 40 pulses increased the cutting speed, but the fragile phases introduced by HCPEB treatment in insert have detrimental side effect.

\section{Acknowledgments}

The authors would like to acknowledge the support from the National Science and Technology Major Project of China (2012ZX04003-061).

\section{REFERENCES}

1. Leyens, C., Peters, M. Titanium and Titanium Alloys: Fundamentals and Applications. Wiley-VCH Verlag GmbH \& Co. KgaA, Weinheim, 2003: pp. 1-36. http://dx.doi.org/10.1002/3527602119

2. Elias, C. N., Lima, H. C., Valiev, R. M., Meyers, A. Biomedical Applications of Titanium and Its Alloys JOM 60 (3) 2008: pp. 46 - 49.

3. Ezugwu, E. O., Wang, Z.-M. Titanium Alloys and Their Machinability a Review Journal of Materials Processing Technology 68 (3) 1997: pp. 262 - 274. 
4. Che-Haron, C. H., Jawaid, A. The Effect of Machining on Surface Integrity of Titanium Alloy Ti-6\%Al-4\%V Journal of Materials Processing Technology 166 (2) 2005: pp. $188-192$.

http://dx.doi.org/10.1016/j.jmatprotec.2004.08.012

5. Ghani, J. A., Che-Haron, C. H., Hamdan, S. H., Said, A. Y. M., Tomadi, S. H. Failure Mode Analysis of Carbide Cutting Tools Used for Machining Titanium Alloy Ceramics International 39 (4) 2013: pp. 4449-4456.

6. Zhang, S., Li, J.-F., Sun, J., Jiang, F. Tool Wear and Cutting Forces Variation in High-speed End-milling Ti-6Al-4V Alloy International Journal of Advanced Manufacturing Technology 46 (1-4) 2010: pp. 69-78.

7. Lee, K.-H., Cha, S.-I., Kim, B.-K., Hong, S.-H. Effect of WC/TiC Grain Size Ratio on Microstructure and Mechanical Properties of WC-TiC-Co Cemented Carbides International Journal of Refractory Metals \& Hard Materials 24 (1) 2006: pp. 109-114. http://dx.doi.org/10.1016/j.ijrmhm.2005.04.018

8. Zhang, K.-M., Zou, J.-X., Grosdidier, T., Gey, N., Yang, D.-Z., Hao, S.-Z., Dong, C. Surface Modification of Ni (50.6 at.\%) Ti by High Current Pulsed Electron Beam Treatment Journal of Alloys and Compounds 434-435 2007: pp. $682-685$.

9. Hao, S.-Z., Wang, H.-H., Li, M.-C., Xu, Y., Dong, C. Enhanced Surface Properties Induced by High Current Pulsed Electron Beam (HCPEB) Treatment Rare Metal Materials and Engineering 40 (4) 2011: pp. 178-180. http://dx.doi.org/10.4028/www.scientific.net/msf.675677.1205

10. Guan, Q.-F., Zhang, Q.-Y., $\quad$ Dong, C., Zou, G.-T. Deformation Twining in Single-crystal Aluminum Induced by High-current Pulsed Electron Beam Journal of Materials Science 40 (18) 2005: pp. 5049-5052.

11. Gao, Y.-K. Surface Modification of $\mathrm{TC}_{4}$ Titanium Alloy by High Current Pulsed Electron Beam (HCPEB) with Different Pulsed Energy Densities Journal of Alloys and Compounds 572 2013: pp. 180-185.

12. Gao, Y.-K. Surface Modification of TA2 Pure Titanium by Low Energy High Current Pulsed Electron Beam Treatments Applied Surface Science 257 2011: pp. 455-7460.

13. Gao, Y.-K. Influence of Pulsed Electron Beam Treatment on Microstructure and Properties of TA15 Titanium Alloy Applied Surface Science 264 2013: pp. 633-635. http://dx.doi.org/10.1016/j.apsusc.2012.10.083

14. Xu, Y., Zhang, Y., Hao, S.-Z., Perroud, O., Li, M.-C., Wang, H.-H., Grosdidier, T., Dong, C. Surface Microstructure and Mechanical Property of WC-6\%Co Hard
Alloy Irradiation by High Current Pulsed Electron Beam Applied Surface Science 279 2013: pp. 137-141.

15. Hao, S.-Z., Xu, Y., He, D.-Y., Dong, C. Microstructure and Properties of YG8 Hard Alloy after High Current Pulsed Electron Beam Irradiation Heat Treatment of Metals 36 (3) 2011: pp. 68-71.

16. Proskurovsky, D. I., Rotshtein, V., Ozur, G. E., Markov, A. B., Nazarov, D. S. Pulsed Electron-beam Technology for Surface Modification of Metallic Materials Journal of Vacuum Science \& Technology A 16 (4) 1998: pp. $2480-2488$.

17. Uglov, V. V., Kuleshov, A. K., Soldatenko, E. A., Koval, N. N., Ivanov, Yu. F., Teresov, A. D. Structure, Phase Composition and Mechanical Properties of Hard Alloy Treated by Intense Pulsed Electron Beams Surface and Coatings Technology $206(11-12)$ 2012: pp. 2972-2976.

18. Zhang, L., Chen, S., Cheng, X., Wu, H.-P., Ma, Y., Xiong, X.-J. Effects of Cubic Carbides and La Additions on WC Grain Morphology, Hardness and Toughness of WC-Co Alloys Transactions of Nonferrous Metals Society of China 22 (7) 2012: pp. 1680-1685. http://dx.doi.org/10.1016/S1003-6326(11)61373-3

19. Grosdidier, T., Zou, J.-X., Bolle, B., Hao, S.-Z., Dong, C. Grain Refinement Hardening and Metastable Phase Formation by High Current Pulsed Electron Beam (HCPEB) Treatment under Heating and Melting Modes Journal of Alloys and Compounds 504 2010: pp. 508-511.

20. Hao, S.-Z., Zhang, Y., Xu, Y., Gey, N., Grosdidier, T., Dong, C. WC/Co Composite Surface Structure and Nano Graphite Precipitate Induced by High Current Pulsed Electron Beam Irradiation Applied Surface Science 285 2013: pp. $26230-26235$.

21. Ungar, T., Gubicza, J. Nanocrystalline Materials Studied by Power Diffraction Line Profile Analysis Zeitschrift fuer Kristallographie 222 2007: pp. 114-128.

22. Tai, W.-P., Watanabe, T. Fabrication and Mechanical Properties of $\mathrm{Al}_{2} \mathrm{O}_{3}-\mathrm{WC}$-Co Composite by Vacuum Hot Pressing Journal of the American Ceramics Society 81 1998: pp. 1673-1676.

23. Kiritani, M., $\quad$ Satoh, Y., $\quad$ Kizuka, Y., $\quad$ Arakawa, K., Ogasawara, Y., Arai, S., Shimomura, Y. Anomalous Production of Vacancy Clusters and the Possibility of Plastic Deformation of Crystalline Metals without Dislocations Philosophical Magazine Letter 79 (10) 1999: pp. $797-804$. http://dx.doi.org/10.1080/095008399176616

24. Kiritani, M. Dislocation-free Plastic Deformation under High Stress Materials Science and Engineering A 350 (1-2) 2003: pp. $1-7$. 